\title{
Assessing Barriers to Expansion of Farm-to-Chef Sales: A Case Study from Upstate New York
}

\author{
Todd M. Schmit (Corresponding author) \\ Charles H. Dyson School of Applied Economics and Management \\ Cornell University, 437 Warren Hall, Ithaca, NY 14853, USA \\ Tel: 1-607-255-3015 E-mail: tms1@cornell.edu
}

Stephen E. Hadcock

Cornell Cooperative Extension, Columbia County

479 Rte. 66, Hudson, NY 12534, USA

Tel: 1-518-828-3346 E-mail: seh11@cornell.edu

Received: September 2, 2011

Accepted: September 15, $2011 \quad$ Published: February 1, 2012

doi:10.5539/jfr.v1n1p117

URL: http://dx.doi.org/10.5539/jfr.v1n1p117

This research is financed, in part, by Cornell Cooperative Extension of Columbia County and the Cornell University College of Agriculture and Life Sciences/Cornell Cooperative Extension Summer Internship Program.

\begin{abstract}
Columbia County Bounty is a local organization made up of farmer and culinary business members, with a mission that includes promoting connections between local agricultural producers and culinary businesses. A case study was conducted to address questions raised by CCB related to expanding farm-to-chef marketing in their area. Common barriers for restaurants included larger time commitments, inconvenience, and consistency in product volumes and quality; however, satisfaction with local wholesale distributors may create new opportunities for farmers to work collaboratively with them in including more local products in their distribution. A closer inspection of channel performance by farms in the study will drive changes in future channel strategies and utilization of farm-to-chef marketing, as farms are already benefiting from strong direct marketing channels and restaurants procuring local products from these channels.
\end{abstract}

Keywords: Farm-to-chef, Local food, Marketing channels

\section{Introduction}

It was the Taste of Columbia County banquet in the fall of 2008, the first of what would eventually be an annual event organized by Columbia County Bounty (CCB) in upstate New York to celebrate the year's harvest of local agricultural products and to promote awareness of local foods in the community. CCB's Executive Director attended, along with approximately 25 local farmers, 20 chefs, and 150 community members. CCB members include both farmers and culinary business representatives, with a collective mission to promote networking connections between local agricultural producers and culinary businesses, as well as to educate the community about local and regional food products. The Executive Director was considering future changes in CCB operations to improve on its mission and increase the utilization of local agricultural products in the region's culinary businesses.

Unfortunately, CCB lacked the information and resources needed to address these issues. Since the formal creation of CCB in 2007, the group knew of only anecdotal evidence of the success of enhancing business-to-business relationships of farmers and chefs. A better understanding of the current utilization of farm-to-chef marketing channels by local farmers and culinary businesses was needed, along with how this channel fits into the overall sales and procurement channel strategies of its members. The county has a relatively 
strong influx of tourists and part-time residents in the summer and fall. Knowing how these consumers view the use of local foods at restaurants is an important demand-side component in understanding consumer dining patterns and the potential premiums for local food offerings. Finally, a current examination of potential barriers to entry or expansion in this channel was needed to help capitalize on growing local marketing opportunities.

Previous literature has shown that marketing of farm products to local restaurants can present opportunities for increased farm sales and broadened consumer exposure to local farming operations (Lawless, 2001; Thilmany, 2004; Curtis \& Cowee, 2009). Ancillary benefits of selling to restaurants have also been identified; e.g., insight into current market trends and changing consumer demands for food products (Pepinsky and Thilmany, 2004), and enhancing brand development and product differentiation for producers whose operations and products are featured on their clients' menus (Curtis \& Cowee, 2009). However, generalizing the success of these types of efforts is difficult given differences in farmer goals and expectations, and performance-relevant heterogeneity in spatial market conditions. Specialized and/or spatially unique market conditions often necessitate these types of evaluations on a case-by-case basis.

These issues are the focus of this case study. In the summer of 2009, a study using data collected in Columbia County was initiated to address the issues brought forward by CCB. While the focus area was relatively small and consideration of unique market conditions in the area will be important, it was hoped that a broader understanding of this marketing channel as a component of overall marketing strategies adopted by farms could be achieved. By gathering and analyzing information from all relevant stakeholders (i.e., farmers, culinary business managers, and restaurant patrons), we hoped to provide a more comprehensive perspective than previous studies. While the results are likely not generalizable across areas with sufficiently different market conditions, our results should provide some evidence of the resiliency (or lack thereof) of barriers identified in previous work.

The approach includes an evaluation of farm-to-chef activities within the context of other local food market institutions. Specifically, information was gathered on the relative importance of farmer sales in different market channels, on alternative procurement sources used by restaurants, and on the utilization of alternative local food outlets by residents in the study area. Such an approach should facilitate a more comprehensive assessment necessary for these types of marketing institutions.

\section{Case Study Area}

Columbia County is located in the Hudson Valley region of New York State (NYS) (Figure 1). Given its diversity of agriculture and geographic location to large metropolitan markets, agricultural industries appear well positioned to take advantage of growing local food demands. Soils and climate allow for wide variety of crop and animal production. Of the 62 counties in NYS, the county ranks in the middle for total agricultural receipts, including both crop and livestock products (USDA, 2009). It ranks ninth in sales of fruits, tree nuts, and berries, thirteenth in poultry and eggs, and first in sheep and goat products. The county also has the sixth highest acres of apples. Within the ten-county southeast region of NYS (the first 'upstate' region above the New York City metropolitan area), Columbia County ranks third in agricultural receipts, fifth in number of farms and second in the total land on farms (USDA, 2009).

(Figure 1)

Its relatively close proximity to major metropolitan areas also makes Columbia County an attractive area for downstate tourists to visit and some to live in the area for part of the year with second homes. Columbia County median household income is about eight thousand dollars higher than NYS counties of similar population size $(61,618 \pm 10,000$ residents) (U.S. Census Bureau, 2010). The area is also easily accessible to visitors and residents by a good road system and rail services to and from the metropolitan area downstate. These factors have opened up additional marketing opportunities for farmers and other businesses in the local food system.

Columbia County has shown particularly strong growth in direct to consumer (D2C) sales by farmers relative to the state and U.S. in aggregate (Note 1). Specifically, the number of farms selling at least a portion of their farm sales D2C increased by $29 \%$ from 2002 to 2007 (USDA, 2009). These numbers compare with $15 \%$ and $17 \%$ for NYS and the U.S., respectively. By 2007, nearly one-quarter of all farms in the county (23\%) participated in D2C sales channels that contributed over $6 \%$ of all reported farms sales. In comparison, $15 \%$ and $6 \%$ of farms in NYS and the U.S., respectively, had D2C sales that made up less than $2 \%$ and $0.5 \%$ of total farm sales.

\section{Previous Evidence}

The development of defined purchasing specifications and delivery schedules, and a sufficient level of communication skills among all parties to facilitate and maintain information exchange are well-established 
components of effective wholesale marketing. In addition, some wholesale channels (e.g., distributors or larger food service providers) may provide a timely outlet for producers with excess supplies of perishable products in a high-production season (Thilmany, 2004). Smaller product commitments through smaller restaurants may facilitate easier entry into local food markets for some farmers.

Studies focusing on a restaurant's decision to purchase local products generally find that product attributes related to taste or quality and the dependability of farmer suppliers were most important (Benepe, et al., 2001; Thilmany, 2004; Curtis and Cowee, 2009). Inconvenient ordering, ineffective communication skills, and higher product costs have also been cited as important impediments (Feenstra, et al., 2003; Curtis \& Cowee, 2009). Purchasing patterns of local food products can vary significantly by the type of restaurant; e.g., Curtis \& Cowee (2009) found that smaller or independently owned restaurants should be targeted due to higher purchases of local products.

Seasonality in cropping seasons, weather-dependent harvest quantities and quality, and unexpected changes in buyer demands are often concerns expressed by farmers that can be problematic when trying to establish marketing agreements with restaurants (LeRoux, et al., 2010). Culinary businesses must oftentimes procure products from multiple sources to meet demands of their clientele. While this can represent competition for local producers, some ingredients are simply not available from local sources given local growing conditions or time of the year. However, this multiple-buyer dimension can provide opportunities for local producers to better differentiate their products through unique attributes, including freshness and quality (Thilmany, 2004).

\section{Data Collection}

Mail surveys were designed and distributed to agricultural producers and culinary businesses in Columbia County in summer 2009. Restaurant patrons were also surveyed at four participating restaurants, located in different towns within the county. Surveys were distributed in June and follow-up contacts were made throughout the summer to aid in survey response (Note 2). Surveys were distributed to 120 producers that utilized wholesale and/or retail marketing channels beyond traditional homogenous commodity-based channels. In total, 25 surveys were returned (21\%), of which eight marketed farm products to restaurants.

Surveys were distributed to 92 restaurants, including full- and limited-service restaurants and specialty/catering food service establishments. In total, 10 surveys were returned $(11 \%)$, of which nine bought directly from farmers (Note 3). Finally, patron surveys were conducted in four participating restaurants; each of the restaurants were located in different towns within the county; consumers were limited to completing one survey (Note 4). In total, 36 surveys were returned.

\subsection{Farm summary}

Farms returning surveys were generally smaller than the average farm size in the area, but more typical of farms concentrating on direct market sales. Farms employed a median of about two employees, $N=22$, and had 23 acres under cultivation, $N=21$, (Note 5 ). The types of products marketed across farms that did and did not sell to restaurants were very similar. This was expected given that many of the same products are marketed across multiple channels. Across all farms $(N=25), 18$ farms sold fruits and vegetables, 11 sold meat or egg products, and nine sold processed foods, e.g. preserves, breads, wine, cider. Only two farms marketed dairy products. Several farms marketed products in multiple categories.

The number of years farms had been selling to restaurants $(N=8)$ ranged from one to 15 years, and included between one and six individual restaurant customers. The value of sales and number of weeks sold per year were equally varied; some sold to restaurants only a few times per year with limited sales, while others sold to restaurants for more than 40 weeks per year. With available data, we cannot disentangle the sources of this variation; e.g., specific products marketed (fresh versus processed/frozen products), technology adoption by farmers (high tunnels, greenhouses), or management/marketing skills and effort.

To better understand channel utilization strategies adopted by producers, respondents were asked to identify all market channels they participated in and their relative contributions to total farm sales. Of the 25 farms surveyed, farm stands and farmers markets were the most commonly utilized; i.e., used by 20 and 13 farms, respectively (Table1). In addition to the eight farms selling to restaurants, six farms sold to packers/distributors, grocery/specialty stores, or to other farmer vendors. With the exception of sales to other farmer vendors, retail channels, on average, contributed more to total farm sales than wholesale channels for this sample (Table 1). However, individual farm results varied greatly (e.g., percentages of total farm sales at farmers markets ranged from $5 \%$ to $85 \%$; while packer/distributor sales ranged from $2 \%$ to $30 \%$ ).

(Table 1) 
The total number of channels utilized by farms was about three; farms selling to restaurants utilized between four and five total channels (on average), while those that did not utilized between one and two. Thus, for our sample, farms that sold to restaurants were also farms that tended to adopt more diversified channel strategies in general. The distribution of sales was weighted more heavily on direct channels compared to a similar study of farmers market vendors in Northern New York (Schmit \& Gomez, 2011). However, the socio-economic and demographic statistics of the market areas were quite different.

The relatively strong reliance on direct marketing channels for this sample may also influence the low utilization of restaurant channels. While higher prices often attract farmers to direct marketing channels, marketing labor costs tend to be higher as well (LeRoux, et al., 2010; Hardesty \& Leff, 2010). For a group of farms already involved in a fair amount of time-consuming direct marketing, expanding sales into the restaurant channel may be less feasible given time constraints, particularly if expected sales volumes are low. For the eight farms in our sample utilizing this channel, the average contribution to total farm sales was only $6 \%$ (the median was $2 \%$ ) (Table 1).

\subsection{Restaurant summary}

Responding restaurants $(N=10)$ represented a range of ages, sizes, and local farm product purchasing styles. Six of the culinary businesses were full-service restaurants, with the remainder either limited-service restaurants or specialty food service providers (e.g., caterers). The average age of the businesses was about 10 years (the median was 5), but ranged from first-year operations to those operating for more than 25 years. Businesses served around 300 customers per week, on average, and ranged from as few as 75 to more than 500 .

Four of the eight restaurants buying from local farmers consistently purchased from them for as long as they have been in operation, the rest for about one-half of that time. Delivery frequencies ranged from once per month to six times per week. The number of farmers restaurants purchased from did not appear to be correlated with restaurant size, and ranged from as few as two to as many as twenty. How restaurants choose the farms and number they purchase from is beyond the scope of the data available; however, in general, will depend on a number of factors beyond restaurant size; e.g., types of meals and clientele, volume and quality of products required, availability and costs of local products, and philosophy in using local products.

Most restaurants purchased directly from farmers for a limited number of weeks per year (around 20), similar to annual fresh product marketing windows for local direct marketing channels in the area; however this ranged from as low as one to every week per year. Consistent with the farmer results, fresh fruits and vegetables purchases were most common; however, some restaurants purchased meat, dairy, and other processed food products (e.g., sauces, preserves, breads) that supported higher numbers of purchase weeks.

A number of procurement sources were used by the restaurants in this sample (Table 2). Importantly, all restaurants used at least one kind of wholesale distributor, including nine that used local distributors and six that used regional or national distributors. With the exception of direct farmer arrangements, wholesale distributor channels were associated with the largest shares of ingredient purchases. Purchases by restaurants using local distributors were, on average, $55 \%$ of all product purchases, regional or national distributors were about $25 \%$.

Restaurants buying from farmers used a number of different channels to procure food products - six used direct farmer arrangements, four purchased from roadside stands, and one was a member of a CSA. However, these other sources of local products represented much lower shares of total product purchases $(6 \%$ to $12 \%$, on average) than direct purchase arrangements with farmers ( $27 \%$, on average).

(Table 2)

\subsection{Restaurant patron summary}

Responding patrons ( $N=36$ ) were roughly $40 \%$ male and $60 \%$ female, and represented a broad age range. The group was relatively well educated, with nearly one-half completing undergraduate or graduate degrees, and nearly three-quarters with annual household incomes above $\$ 75,000$. To help understand consumer attitudes for this sample towards the use of local foods in restaurants, patrons were asked how strongly they agreed with a variety of statements. A selection of those statements and their average agreement scores are shown in Table 3 (Note 6). The average scores reflecting patron 'wishes' that restaurants utilize more local food products was 1.7, and, expectedly, was not statistically different than the average agreement score that customers 'prefer' to eat at restaurants that serve foods prepared with local ingredients (1.6). This makes sense as both statements reflect consumer preferences more generally, perhaps getting at normative or altruistic expectations.

(Table 3) 
Average agreement scores dropped more precipitously when action-specific statements were proposed. Specifically, the average agreement score drops to 1.3 when customers were asked whether they were 'willing to pay more' for meals prepared with local products (Table 1), and to 1.1 when asked if they 'eat more frequently' at restaurants that serve foods prepared with local products. While the willingness-to-pay and eating frequency statement scores are not statistically different from one another, they are both below the scores when wishes and preferences were proposed.

These results provide evidence, at least modestly given sample size considerations, that while customers generally supported increased utilization of local foods at restaurants, they were more resistant to actually changing dining frequencies or willingness to pay for restaurant meals based on this factor alone. This may be due, in part, to the availability of local food products through other direct marketing channels in the area. Of the 36 restaurant patrons, 29 purchased local food products in grocery or specialty stores, 25 at farmers markets, 20 at roadside stands, 16 at u-pick operations, and 9 through CSAs.

\section{Channel Barriers}

No clear consensus emerged from farmers when asked whether existing barriers were preventing them from expanding (or starting) sales through the farm-to-chef market channel. The number that agreed (7) was only slightly above those that did not (6), and the rest were indifferent (8). However, the results appear consistent with responses from those currently selling to restaurants in that four expected sales though this channel to increase next year, two expected no change, and two expected sales to decrease.

Alternatively, restaurants appeared more concerned - seven agreed that barriers were preventing them from expanding farm purchases, and only two disagreed. Interestingly, only three of the nine restaurants reported that using local food products in their businesses actually increased overall restaurant sales; the rest said it had no effect. While consistent with the patron survey results discussed earlier, this small sales effect would seem to question if expanding purchases through this channel would improve overall returns. We lack sufficient information to address this question fully. Choosing the appropriate marketing mix for farmers includes consideration of many factors such as sales, profits, risk, and lifestyle preferences; the weights assigned to these factors are unique to the individual (LeRoux et al., 2010). The same can arguably said for the restaurants in our sample.

Farmers and restaurants were asked to identify what barriers currently exist to expanding (or initiating) farm-to-chef marketing/procurement for their operations. The responses are summarized in Table 4. For restaurants, time constraints and the inconvenience of dealing with multiple farmers was cited most frequently (6), followed by product quality and consistency concerns (5) and the availability of sufficient volumes of product (4). These results are similar to previous studies. However, in deference to previous literature, issues related to costs and communication problems appear less problematic for this sample. In addition, four of the nine restaurants said they were simply satisfied with their current distributors and were not actively seeking new suppliers.

(Table 4)

Similar to recent literature, farmers in our sample commonly cited barriers involving time constraints and inconvenience of delivering to (multiple) restaurants (10), as well as concern whether adequate prices could be received, particularly when delivery costs are considered (8). However, restaurant interest/availability in the area (4) and inflexible delivery requirements regarding volumes and quality were of lower concern overall relative to other areas. Unique attributes of the study area discussed above likely drives this result, particularly since the most highly cited barriers for our sample involved farmers that were satisfied with their existing market strategies (12) and/or were already selling all of their production to existing buyers.

\section{Discussion}

The area of Columbia County has seen strong growth in demand for local foods as reflected in D2C census data and the number of direct marketing channels employed by the surveyed farmers. Higher household incomes and tourist activity in the area likely contributes to farms in this sample weighing more heavily on direct marketing channels, particularly farmers markets and farm stands. Notably, these were also venues frequented by some of the surveyed restaurants as a place to procure local farm ingredients. While eight of our surveyed farmers utilized the wholesale restaurant channel, it tended to contribute a relatively low amount to total farm sales. Wholesale distributors were used by less farms in total, but tended to contribute more to farm sales. Notably, the largest use of wholesale channels, in terms of sales, was to other farmers who presumably used the products to expand their direct market offerings. 
Sampled restaurants tended to utilize local food products as a relatively larger share of their total product purchases than would be implied by our farm survey results, presumably made up by the use of multiple farmer arrangements and/or integration with farm purchases available in other direct marketing outlets. That said, distributors (local, regional, or national) were still needed to augment local purchases in meeting the demands of their clientele. A sample of restaurant patrons at these types of restaurants also revealed some resistance to altering dining purchase locations or frequencies and willingness to paying higher prices for restaurants using local food products. In fact, most restaurants surveyed indicated that including local food products on their menus had no effect on sales whatsoever. This may be due to a wider presence and availability of local food purchasing opportunities for consumers in the area.

Common barriers cited by both agents involved a lack of time and inconvenience of dealing with multiple buyers/sellers and lower product volumes. Product availability, quality, and consistency surfaced as relatively strong barriers to restaurants expanding purchases, but these issues were much less problematic for farmers since they were experiencing strong sales through other outlets and satisfied with their existing channel strategy. Concern about changing processing procedures or the types of products offered for restaurants was not appealing to farmers when considering expansion to a channel where prices offered may not cover the additional costs, including delivery. Paying higher prices to farmers was less problematic for restaurants, relative to one-stop-shopping and availability provided by current distributors.

\section{Conclusions}

Relative to other areas of the state and country, Columbia County is unique in its strong presence of direct marketing opportunities for local food products. Purchasing patterns by restaurants with farmers varied greatly in our sample and stronger conclusions explaining these variations would benefit from a larger sample of culinary businesses in the area. Similar to other studies, however, common barriers such as larger time commitments, inconvenience, and consistency in product volumes and quality were revealed. The minimal effects on restaurant sales from using local ingredients and consumer willingness to pay also need further investigation for an area with presumably strong consumer attitudes towards utilization of local foods.

Restaurant satisfaction with current wholesale distributors may create opportunities for local farmers to work collaboratively with local distributors by including more food products from local farmers in their distribution. However, this will require time and attention to volume requirements and delivery schedules, as well as revising post-harvest processing practices to meet food safety regulations and procurement procedures with larger wholesale clients.

Given farmers are generally satisfied with existing marketing channels in the area, the restaurant channel would be more likely to enter into a farm's channel strategy as a replacement to an existing channel, rather than an addition to the channels already utilized. Expected lower volumes at restaurants and insufficient prices to cover the additional marketing costs will likely hinder those expectations, particularly in an area where restaurants have alternative sources from which to procure local food product ingredients.

\section{References}

Benepe, C., Auld, G., Lamm, D., Smith, K., Starr, A., \& Wilken, K. (2001). Cultivating local foodlinks: Barriers and motivators for restaurants and institutional food services to purchase locally grown foods. Presented at Society for Nutrition Education Annual Meeting, Oakland, CA.

Curtis, K. R., \& Cowee, M. (2009). Direct marketing local food to chefs: chef preferences and perceived obstacles. Journal of food distribution research, 40 (2), 26-36.

Feenstra, G., Ohmart, J., \& Chaney, D. (2003). Selling directly to restaurants and retailers: Discussion summary. Davis, CA: University of California Sustainable Agriculture Research and Education Program.

Hardesty, S. D. Leff, P. (2010). Determining marketing costs and returns in alternative marketing channels. Renewable agriculture and food systems, 25, 24-34.

Lawless, G. (2001). Home Grown Wisconsin: The study of a new producer cooperative. In M. Holmes, N. Walzer, \& C.D. Merrett (Eds.), New generation cooperatives: Case studies (pp. 95-108). Malcomb, IL: Illinois Institute for Rural Affairs.

LeRoux, M. N., Schmit, T. M., Roth, M., \& Streeter, D. (2010). Evaluating market channel options for small-scale fruit and vegetable producers. Renewable agriculture and food systems, 25, 16-23. http://dx.doi.org/10.1017/S1742170509990275 
Pepinsky, K., \& Thilmany, D. (2004). Direct marketing agricultural products to restaurants: The case of Colorado Crop to Cuisine. Agricultural Marketing Report AMR-04-03, Fort Collins, CO: Department of Agricultural and Resource Economics, Colorado State University.

Schmit, T. M., \& Gómez, M. I. (2011). Developing viable farmers' markets in rural communities: An empirical investigation of vendor performance using objective and subjective valuations. Food policy, 36, 119-127. http://dx.doi.org/10.1016/j.foodpol.2010.10.001

Thilmany, D. (2004). Colorado Crop to Cuisine. Review of agricultural economics, 2, $404-416$. http://dx.doi.org/10.1111/j.1467-9353.2004.00188.x

U.S. Census Bureau. (2010). 2005-2009 American Community Survey 5-year estimates: County estimates for New York State [Data file]. URL http://www.census.gov/acs/www/

United States Department of Agriculture (USDA). (2009). The Census of Agriculture: 2007 Census highlights, state and county profiles [WWW http://www.agcensus.usda.gov/Publications/2007/Online_Highlights/County_Profiles/New_York/cp36021.pdf

\section{Notes}

Note1. Direct-to-Consumer sales (D2C) represent the value of agricultural products sold directly to individuals for human consumption from roadside stands, farmers' markets, pick-your-own sites, etc. It excludes non-edible products such as nursery crops, flowers, and wool but includes livestock sales. Sales of agricultural products by vertically integrated operations through their own processing and marketing operations are also excluded (USDA, 2009).

Note 2. Copies of the restaurant, farmer, and patron surveys are available from the corresponding author upon request.

Note 3. The authors recognize the limitations of empirical analyses afforded by the small sample sizes; representativeness to the population of NYS should not be inferred and generalizations of the results beyond the sampled firms are necessarily restricted.

Note 4. Each restaurant was given a packet of surveys that they distributed based on their own preferences; e.g., some left them by the register or at the entrance to the restaurant and asked patrons to fill them out before they left; others had servers hand them to the patrons at their table at the end of the meal.

Note 5. We generally report median values since averages can be strongly influenced by outlier observations in small samples.

Note 6. Response categories included strongly disagree, disagree, neither agree nor disagree, agree, and strongly agree. Numeric values were assigned to each category as $-2,-1,0,1$, and 2 , respectively, to compute average scores. Confidence intervals (CI) were computed assuming mean responses are normally distributed; i.e. $90 \% \mathrm{CI}$ $=$ average score $\pm 1.645^{*}$ standard error. 
Table 1. Utilization of Alternative Sales Market Channels by Farmers ${ }^{\text {a }}$

\begin{tabular}{|l|c|c|c|}
\hline & Number & \multicolumn{2}{|c|}{ Percent of Total Farm Sales } \\
\hline Channel & of Farms & Median & Mean \\
\hline Retail Channels: & & & \\
\hline Famers market & 13 & 62 & 50 \\
\hline Farm stand & 20 & 40 & 47 \\
\hline U-pick & 4 & 20 & 34 \\
\hline CSA & 3 & 40 & 54 \\
\hline Other & 3 & 3 & 3 \\
\hline & & & \\
\hline Wholesale Channels: & & & 6 \\
\hline Restaurant & 8 & 2 & 18 \\
\hline Packer/Distributor & 6 & 10 & 5 \\
\hline Grocery/Specialty & 6 & 4 & 39 \\
\hline Other farm vendors & 6 & 40 & \\
\hline
\end{tabular}

${ }^{\text {a }}$ Includes all responding farms, $N=25$. Sales percentages are of utilizing farms only.

Description of the utilization of alterative market channels and their relative contribution to total farm sales.

Table 2. Utilization of Alternative Procurement Channels by Restaurants ${ }^{\text {a }}$

\begin{tabular}{|l|c|c|c|}
\hline & Number & \multicolumn{2}{c|}{ Percent of Total Purchases } \\
\hline Channel & of Restaurants & Median & Mean \\
\hline Local distributors & 9 & 55 & 54 \\
\hline Regional/National distributors & 6 & 25 & 36 \\
\hline Direct farmer arrangements & 6 & 25 & 27 \\
\hline Roadside stands & 4 & 10 & 12 \\
\hline Farmers markets & 3 & 6 & 7 \\
\hline CSAs & 1 & 10 & 10 \\
\hline
\end{tabular}

${ }^{a}$ Includes all responding restaurants, $N=10$. Purchase percentages are of utilizing restaurants only.

Description of the utilization of alternative procurement channels and their relative contribution to total restaurant ingredient purchases.

Table 3. Average Agreement Scores of Alternative Local Food Restaurant Statements ${ }^{\text {a }}$

\begin{tabular}{|l|c|c|}
\hline Statement & $\begin{array}{c}\text { Average } \\
\text { Score }\end{array}$ & $\begin{array}{c}90 \% \text { Confidence } \\
\text { Interval }\end{array}$ \\
\hline I wish restaurants would utilize more local food products in their menus & 1.71 & {$[1.57,1.86]$} \\
\hline $\begin{array}{l}\text { I prefer to eat at restaurants that have food prepared with local food } \\
\text { products. }\end{array}$ & 1.57 & {$[1.40,1.74]$} \\
\hline I am willing to pay more for meals prepared with local food products. & 1.26 & {$[1.05,1.46]$} \\
\hline $\begin{array}{l}\text { I eat more frequently at restaurants that have foods prepared with local } \\
\text { foods. }\end{array}$ & 1.10 & {$[0.86,1.33]$} \\
\hline
\end{tabular}

${ }^{a}$ Includes all responding restaurant patrons at four participating restaurants, $\mathrm{N}=36$. Average agreement scores computed using five-category scale: strongly agree (2), agree (1), neither agree nor disagree (0), disagree (-1), and strongly disagree (-2). Confidence intervals assume responses are normally distributed.

Description of restaurant patron opinions towards local foods and impacts on their dining decisions. 
Table 4. Barriers Cited by Restaurants and Farmers Limiting Restaurant Channel Expansion and Utilization ${ }^{\text {a }}$

\begin{tabular}{|l|c|}
\hline Barrier & Number of Responses \\
\hline Restaurants $(N=9)$ & \\
\hline Do not have time for several farmers, inconvenient & 6 \\
\hline Unsure of product quality or consistency & 5 \\
\hline Unsure of product volumes, insufficient volume & 4 \\
\hline Satisfied with current distributors & 4 \\
\hline Unsure of available farmers, poor communication & 2 \\
\hline Prices are too high & 2 \\
\hline Farms are too far away or do not offer delivery & 2 \\
\hline & \\
\hline Farmers $(N=22)$ & 12 \\
\hline Can sell all that I produce now & 12 \\
\hline Satisfied with existing markets, would have to change processing or products offered & 10 \\
\hline Do not have time to deliver to several restaurants, inconvenient & 8 \\
\hline Unsure if prices will cover extra costs of delivery & 4 \\
\hline Restaurants are not interested or are too far away & 3 \\
\hline Cannot deliver year-round supplies with consistent quality and volume (weather) & 1 \\
\hline Delayed payment for product deliveries & \\
\hline
\end{tabular}

${ }^{a}$ Includes all responding restaurants and famres, the questions were not answered by one restaurant and three farmers.

Description of the barriers given by farmers and restaurants in expanding sales and purchases through the farm to chef restaurant channel.

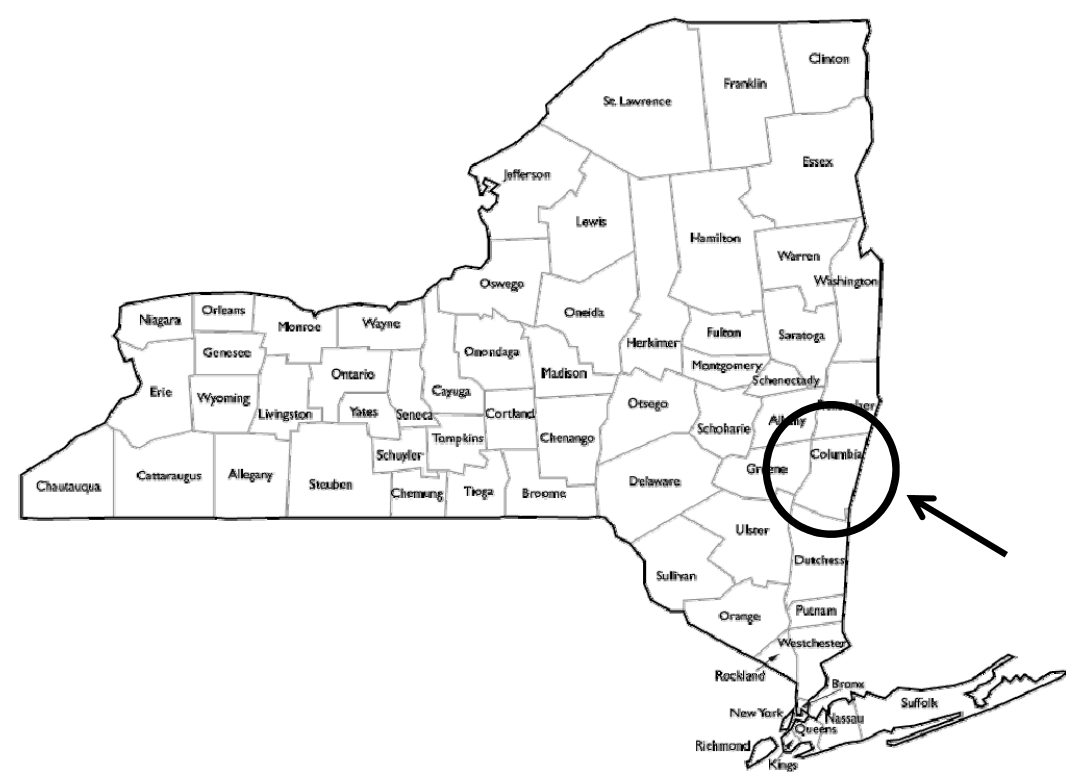

Figure 1. Location of study area, Columbia County, NY, USA

Highlighting the focus area for the case study. 